\title{
Using Herbs and Spices to Increase Vegetable Intake Among Rural Adolescents
}

\author{
Juliana R. Fritts, $\mathrm{MS}^{1}$; Maria A. Bermudez, $\mathrm{BS}^{2}$; Rebecca L. Hargrove, $\mathrm{MS}^{2}$; Laurie Alla, $\mathrm{MS}^{2}$; \\ Clara Fort, $\mathrm{MS}^{2}$; Qihan Liang, $\mathrm{BS}^{2}$; Terri L. Cravener, $\mathrm{MS}^{2}$; Barbara J. Rolls, $\mathrm{PhD}^{2}$; \\ Christopher R. D'Adamo, $\mathrm{PhD}^{3}$; John E. Hayes, $\mathrm{PhD}^{1}$; Kathleen L. Keller, $\mathrm{PhD}^{1,2}$
}

\begin{abstract}
Objective: To test whether adding herbs and spices to school lunch vegetables increases selection and intake compared with lightly salted control versions among rural adolescents.

Design: This study compared intake of vegetables with herbs and spices with lightly salted controls (phase I) and tested whether 5 repeated exposures would increase students' intake of herb and spice seasoned vegetables (phase II).

Participants and Setting: A total of 600-700 students at a rural middle/high school (age 11-18 years). Intervention: In phase I, herbs and spices were added to 8 vegetables and outcomes were compared with 8 control recipes. In phase II, the impact of repeated exposure to herb and spice blends served on different vegetables was assessed.

Main Outcomes: Vegetable selection rates, weighed intake, and willingness to eat again.

Analysis: Two-way ANOVAs tested effects of condition (herbs and spices vs control; before vs after exposure) and age (middle vs high school) on selection and intake.

Results: In phase I, students ate more control than seasoned broccoli $(P=.01)$, cauliflower $(P=.006)$, and green beans $(P=.01)$, and high schoolers generally consumed more seasoned vegetables than did middle schoolers $(P<.03)$. In phase II, repeated exposure to herbs and spices increased reported willingness to eat again for seasoned broccoli $(P=.003)$.

Conclusions and Implications: In a short-term intervention, herbs and spices did not produce robust increases in school lunch vegetable intake among rural adolescents, but limited repeat exposure may increase students' willingness to consume these flavors. Additional work is needed to identify individual and school-level characteristics that affect students' willingness to select and consume vegetables with herbs and spices.
\end{abstract}

Key Words: adolescents, herbs, school, spices, vegetables (J Nutr Educ Behav. 2019; 51:806-816.)

Accepted April 13, 2019. Published online May 15, 2019.

\section{INTRODUCTION}

The National School Lunch Program (NSLP) serves 30 million children each year and provides 33\% of a child's daily energy needs. ${ }^{1}$ Thus, it has a major role in the dietary health of American youths and is an important target for interventions. After implementation of the Healthy Hunger Free Kids Act of 2010, ${ }^{2}$ schools across the US updated their programs to offer larger vegetable portion sizes and greater vegetable variety. $^{3}$ Whereas some schools found an increase in vegetable intake

\footnotetext{
${ }^{1}$ Department of Food Science, Pennsylvania State University, University Park, PA

${ }^{2}$ Department of Nutritional Sciences, Pennsylvania State University, University Park, PA

${ }^{3}$ Department of Family and Community Medicine, Department of Epidemiology and Public Health, Center for Integrative Medicine, University of Maryland, Baltimore, MD

Conflict of Interest Disclosure: The authors' conflict of interest disclosures can be found online with this article on www.jneb.org.

Address for correspondence: Kathleen L. Keller, PhD, Departments of Food Science and Nutritional Sciences, 321 Chandlee Laboratory, University Park, PA 16802; E-mail:

k1k37@psu.edu

(C) 2019 The Author(s). Published by Elsevier, Inc. on behalf of the Society for Nutrition Education and Behavior. This is an open access article under the CC BY-NC-ND license. (http://creativecommons.org/licenses/by-nc-nd/4.0/)

https://doi.org/10.1016/j.jneb.2019.04.016
}

since the new regulations $s^{4,5}$ others saw no change. ${ }^{6}$ Because of the mixed outcomes resulting from the new federal regulations, innovative strategies are needed to facilitate widespread change in vegetable intake.

One potential means to improve vegetable intake may be through the use of herbs and spices. Herbs and spices can enhance the flavor of a food without adding excess sugar, fat, or sodium. They are also shelfstable, which makes them promising for sustainable use within school lunch programs. ${ }^{7}$ They can increase acceptability of reduced-fat foods $^{8}$ and low-sodium soups. ${ }^{9,10}$ In addition, they can increase vegetable selection among adults in cafeteria settings. ${ }^{11}$ These findings in adults suggest that the use of herbs and spices on vegetables served in schools may be a promising 
approach to increase student vegetable consumption.

Vegetables are vital to the diet because they are high in nutrients and low in calories, and their intake contributes to a reduction in chronic disease risk. ${ }^{12}$ Even so, only $2.1 \%$ of American youths are meeting daily vegetable recommendations. ${ }^{13}$ Vegetables remain 1 of the least liked food groups among children, ${ }^{14}$ often owing to deterrents including bitterness, lack of sweetness, and unappealing texture and appearance. ${ }^{15-20}$ To improve vegetable intake at schools, researchers evaluated the effects of gardening programs, ${ }^{21}$ increased vegetable portion sizes, $^{22}$ and repeated exposure. ${ }^{23}$ In addition, 1 study $^{24}$ in preschool-age children found a benefit to using herbseasoned dips to increase raw vegetable intake. Although these programs showed some benefit for improving vegetable intake, current efforts are insufficient to meet federally mandated goals and there is a need to conduct additional studies with herbs and spices in older children. ${ }^{25,26}$

The current study tested the impact of adding herbs and spices to vegetables served in the NSLP as a strategy to increase intake in rural adolescents with minimal prior familiarity with seasoning. ${ }^{27}$ Rural adolescents were targeted because they have higher rates of obesity compared with urban counterparts, ${ }^{28}$ which highlights the need to develop novel strategies to improve dietary intake patterns in this population. When recipes were pilot-tested, high school students liked and preferred vegetables with added herbs and spices over those prepared with minimal salt and oil alone (ie, without herbs and spices). ${ }^{27}$ Because of these promising results, a cafeteria-based intervention was implemented to determine whether adding these recipes to the school lunch line would increase vegetable intake.

\section{METHODS}

\section{Study Design}

The study consisted of 2 phases: (I) a cafeteria intervention in which vegetables with added herbs and spices and lightly salted (control) vegetables were offered on the school lunch line and intake was measured (March to May, 2017), and (II) a follow-up phase to determine whether repeated exposure to specific blends of herbs and spices would increase student vegetable consumption across a semester (October to December, 2017). Before phase I, the researchers assessed school lunch vegetables for baseline selection, intake, and ratings of willingness to eat again to gauge usual intake before the intervention. During phase I, an intervention was conducted to compare students' selection, intake, and reported willingness to eat again of 8 lightly salted control vegetables and 8 vegetables with added herb and spice blends (2 sessions/recipe for 32 total sessions). The order in which students were presented with each vegetable condition (ie, control vs herb and spice) was randomized. For phase II, the impact of repeated exposure on selection, intake, and willingness to eat again was measured for 2 seasoned vegetable recipes (Dillicious Broccoli and Fiesta Black Beans and Corn). Two trials of preexposure measurements and 2 of postexposure measurements were conducted; in between measurement periods, students received 5 exposures to the specific blends of herbs and spices used in these recipes (ie, Dillicious Broccoli, which contained dill weed, garlic powder, onion powder, and black pepper; and Fiesta Black Beans and Corn, which contained cumin, dried oregano, cayenne, garlic powder, and onion powder). The study received approval from the Institutional Review Board of Pennsylvania State University. Written consent from students was not required. Parents were sent an informational letter about the study and passively consented to their child's participation.

\section{Participants}

This study was conducted at a combined middle and high school within a rural Pennsylvania school district composed of about 97\% Caucasian students. $^{29}$ Approximately $75 \%$ of students participated in the school lunch program and $44 \%$ received free or reduced-price lunches because they were at $\leq 185 \%$ of the federal poverty line. ${ }^{30}$ Between 600 and 700 students aged 11-18 years were served lunch in the cafeteria daily from 10:30 to 1 PM; these numbers remained consistent throughout all phases of the study. The first and third lunch periods contained only high school students (ie, aged 14-18 years) and the second lunch contained primarily middle school students (ie, aged $11-14$ years).

\section{Baseline Data Collection}

To collect data on the consumption of vegetables typically served within the cafeteria before the intervention, the researchers measured the intake at baseline of steamed broccoli, California blend (broccoli, cauliflower, and carrots), corn, cheesy cauliflower, baked beans, and assorted raw vegetables served with Ranch dressing. All vegetables were served in 8-oz square black plastic cups. Methods to measure intake were developed based on previous plate waste studies ${ }^{5}$ in cafeterias in a which subset of approximately 30 vegetable cups were preweighed and all returned cups were weighed again. Production records at the school included data on the total pounds of vegetables prepared and the amount left at the end of the day; however, they did not include the number of servings prepared and sold during each lunch period. To confirm that the weights collected by the research team were accurate, they were compared with the total amount sold according to production records at the end of each testing day. Researchers made periodic announcements requesting that students return vegetable cups at the end of lunch to a tray rack that had been divided into sections marked with signs stating Would Eat Again or Would Not Eat Again (Figure 1). This provided the measure of willingness to eat again that enabled students to report quickly whether they would eat the vegetable again, through the placement of the returned cup. Incorporating this novel measure into the baseline phase also allowed an opportunity to pilot test the procedure to ensure student comprehension. During the lunch period, members of the research team were strategically placed by the tray racks 


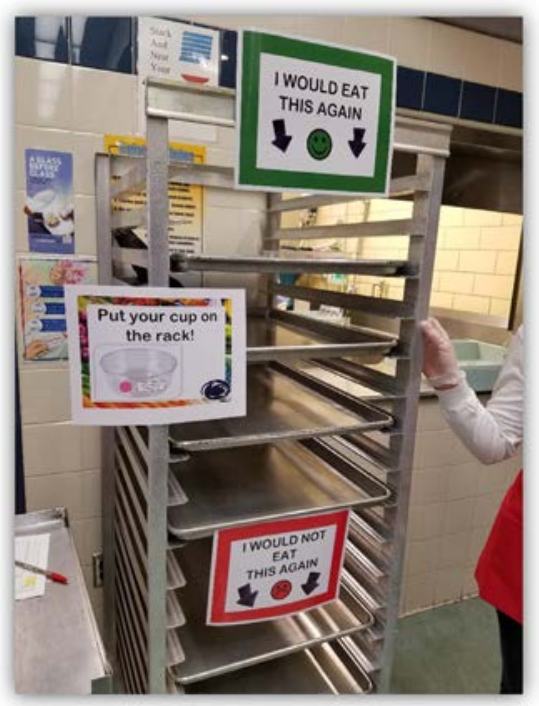

Figure 1. Students reported willingness to eat again by placing trays in the correct place on a designated tray rack. The picture of this tray rack shows the placement of laminated signs with clearly marked wording and facial hedonic descriptors to help students quickly place their tray in the correct spot.

and wastebaskets to remind students to place their vegetable cups on the racks and save any vegetables that were accidentally discarded, and to record observations to assess student compliance. After each lunch period, post-weights were collected for all vegetable cups that were returned. Vegetable selection was determined by adding the number of cups returned to the number that research staff observed students to throw away. Daily selection rates were calculated by dividing the sum of the number of cups returned and seen accidentally thrown away by the total number of vegetable cups sold.

\section{Phase I: Intervention}

Ingredients and recipes used in the intervention were informed by a previous study ${ }^{27}$ conducted in the same school and are detailed in the Supplementary Table. For each vegetable, the control and herb and spice recipes were matched for oil and salt content; all fit within the NSLP guidelines. The addition of a modest amount of salt and oil was essential to enhance the perceived flavor of the herbs and spices and increase their adherence to the target vegetable. To increase the likelihood that schools would continue to use the recipes after the intervention, the vegetables that were chosen were canned (ie, black beans) or frozen (ie, broccoli, carrots, cauliflower, green beans, and corn and peas), with the exception of fresh vegetable combinations served with dips. Before the start of the intervention, the industry partner who developed the recipes conducted a half-day training session with cafeteria staff to demonstrate how to prepare all recipes and allow staff to taste the prepared vegetables. In addition, a detailed illustrated recipe manual was created for the school to help cafeteria staff prepare the recipes after the intervention.

Before each testing day, blends of herbs and spices and the fresh dips were prepared in the laboratory and transported to the school before lunch so that the vegetables could be mixed with spice blends and portioned by research staff in the cafeteria. During the intervention phase, all vegetables were served on the cafeteria line in 8-oz circular clear plastic cups. Although the usual serving size for vegetables at the school was 0.5 cup, to avoid ceiling effects, the serving size was increased to 1 cup for the target vegetables served during the intervention. After portioning and pre-weighing, vegetable servings were covered and placed into holding cabinets until service. To ensure that students knew what the vegetables were, labels for each vegetable type (ie, new plain [vegetable name] or new seasoned [vegetable name]) were added to the serving line. On the lunch line, students were typically provided $2-3$ fruit options (eg, canned fruits, fresh fruits, and $100 \%$ fruit juices daily) and $2-3$ vegetable options (eg, fresh vegetables, steamed vegetable and/or potato product) with the intervention vegetable as 1 of these choices. Vegetable selection, intake, and willingness to eat again were assessed as previously described.

\section{Phase II: Follow-Up Assessment}

The follow-up study tested the influence of repeated exposure to 2 recipes, Dillicious Broccoli and Fiesta Black Beans and Corn, on students' acceptance and intake across a school semester. These recipes were selected by working with the school foodservice director and cafeteria staff, who helped the researchers identify vegetables they were most interested in integrating into the regular menu. Vegetables were prepared, measured, and served using the methods similar to those in the intervention phase, except 8-oz square black plastic containers were used to present vegetables, to improve visual appeal. Baseline intake, selection, and willingness to eat again were measured for each recipe twice during October, 2017 (preexposure) and twice in December, 2017 (postexposure). Between collection dates, 2 blends of herbs and spices were served 5 times on a variety of vegetables over 2 months. In this phase, the 2 herb and spice blends were served with a greater variety of vegetables to prevent the target vegetables from becoming monotonous and to allow cafeteria staff greater autonomy in how they complied with federal regulations. The ultimate goal of these studies was to develop sustainable recipes that might be continued after the intervention, so staff members were encouraged to prepare the vegetables themselves in phase II (ie, effectiveness vs efficacy), although researchers were on-site to check compliance.

\section{Analysis}

For all studies, weights were excluded from analysis if cheese, dressings, or sauces were added to the vegetable cups. Weights were also excluded if vegetables were taken out of the cups by students and/or thrown away. These exclusions accounted for no more than 9 weights removed during an individual testing day. Baseline intake and selection rates were summarized with descriptive statistics. The effect of age group on the willingness to eat again was analyzed using a chisquare goodness of fit test.

To assess the effect of the intervention on vegetable selection and intake, data were averaged across the 2 trial days for each vegetable recipe (control or herb and spice). A 2-way ANOVA was then conducted for each vegetable with either selection or intake as the dependent variables and condition (phase I: control or herb 
and spice; and phase II: baseline or follow-up) and age group (middle or high school) as factors. Fisher's least significant difference (LSD) analyses were conducted for planned comparisons when appropriate. Because the spice blends used on each vegetable were different, each was treated as an independent hypothesis; thus, no Bonferroni adjustment was performed.

To determine the effect of the intervention on students' willingness to eat the vegetable again, Mantel-Haenszel tests were performed with would eat again (yes or no) as the outcome variable, condition (phase I: control or herb and spice; or phase II: baseline or follow-up) as the predictor variable, and age group (middle or high school) as the layered variable.

All statistical analyses were conducted using SPSS Statistics software (version 23, IBM Corporation, Armonk, NY, 2009); $P<.05$ denotes significant differences.

\section{RESULTS}

Baseline Selection, Willingness to Eat Again, and Intake

Of the 625-660 students served daily during the baseline measurement period, $6.6 \%$ to $17.6 \%$ chose the measured vegetable. Of those students, approximately $1.3 \%$ to $8.1 \%$ were in middle school (aged 11-14 years) and $5.3 \%$ to $10.4 \%$ were in high school (aged 14-18 years), depending on the vegetable. The lowest proportion of students chose the California blend (6.6\% total from both age groups), whereas the corn $(17.6 \%)$, cheesy cauliflower $(16.7 \%)$, and fresh vegetables with Ranch dressing (14.8\%) were more frequently selected.

Vegetables consumed in greatest quantities were the cheesy cauliflower (176.5 $\pm 62.8 \mathrm{~g}$ ), baked beans $(164.5 \pm 86.6 \mathrm{~g})$, and fresh vegetables with dip (140.9 $\pm 48.7 \mathrm{~g})$. During cup return, a higher percentage of high school compared with middle school students chose would eat again for 2 vegetables: baked beans $(91.8 \%$ vs $\left.75.7 \%, \chi^{2}[1, \mathrm{n}=86]=4.3 ; P=0.04\right)$ and fresh vegetables served with Ranch dressing $\left(98.2 \%\right.$ vs $91.0 \%, \chi^{2}$ $(1, \mathrm{n}=179)=5.0 ; P=.03)$. Other vegetables did not show an age effect during the baseline period.

Intervention Selection, Willingness to Eat Again, and Intake

Table 1 lists results for intervention selection and willingness to eat again. Because high schoolers consumed more vegetables than did middle schoolers at baseline, all analyses during the intervention were performed with age group (middle or high school) as a between-subjects covariate. There was a significant main effect for age group (F1,60= 40.7, $P<.001$ ) on target vegetable selection but no effect of condition (control or herb and spice) $(P>.05)$ or condition $\times$ age interaction $(P>.05)$. Post hoc tests found that selection rates were greater for high school compared with middle school students regardless of seasoning condition $(P<.001)$.

Mantel-Haenszel tests showed significant differences in students' willingness to eat again for all vegetables except for black beans and corn and fresh vegetables with dip (Table 2).

Intervention Intake of Vegetables With Significant Condition by Age Interactions

Table 2 provides intake results for vegetables with significant condition (plain vs seasoned) $\times$ age interactions; visual representations are shown in Figure 2A. For black beans and corn, there was a main effect of age $(\mathrm{F} 1,97=10.4, P=.002)$ and a condition $\times$ age interaction $(\mathrm{F} 1,97=4.8, P=.03)$ but no main effect

Table 1. Intervention Selection Rates and Willingness to Eat Again percentages Divided by Age Group for Vegetable Conditions (ie, Lightly Salted Control and Added Herbs and Spice)

\begin{tabular}{|c|c|c|c|c|c|c|c|c|c|}
\hline \multirow[b]{2}{*}{ Vegetable } & \multicolumn{2}{|c|}{$\begin{array}{c}\text { Middle School } \\
\text { Selection (\%) } \\
\end{array}$} & \multicolumn{2}{|c|}{$\begin{array}{l}\text { High School } \\
\text { Selection (\%) }\end{array}$} & \multicolumn{2}{|c|}{$\begin{array}{c}\text { Middle School Would } \\
\text { Eat Again (\%) }\end{array}$} & \multicolumn{2}{|c|}{$\begin{array}{l}\text { High School Would } \\
\text { Eat Again (\%) }\end{array}$} & \multirow[t]{2}{*}{$\begin{array}{c}\text { Mantel-Haenszel } \\
\text { (2-Sided) } P\end{array}$} \\
\hline & Plain & Seasoned & Plain & Seasoned & Plain & Seasoned & Plain & Seasoned & \\
\hline Broccoli & 4.2 & 3.6 & 9.4 & 8.5 & 98.1 & 78.3 & 94.9 & 82.9 & $<.001$ \\
\hline Cauliflower & 3.2 & 3.6 & 4.8 & 5.5 & 94.9 & 68.9 & 93.4 & 82.1 & .001 \\
\hline Carrots & 2.3 & 3.1 & 4.4 & 5.9 & 93.1 & 82.9 & 93.0 & 77.9 & .01 \\
\hline $\begin{array}{l}\text { Black beans } \\
\text { and corn }\end{array}$ & 1.1 & 1.0 & 3.6 & 2.6 & 91.7 & 69.2 & 71.7 & 73.5 & .81 \\
\hline Green beans & 4.2 & 3.8 & 7.2 & 7.3 & 95.8 & 89.4 & 97.6 & 88.4 & .02 \\
\hline Corn and peas & 4.0 & 4.7 & 6.1 & 5.8 & 96.1 & 76.3 & 93.6 & 84.5 & .002 \\
\hline $\begin{array}{l}\text { Fresh vegetable } \\
\text { variety } 1 \text { with dip }\end{array}$ & 3.8 & 5.5 & 9.5 & 9.6 & 82.6 & 78.8 & 82.5 & 84.5 & .92 \\
\hline $\begin{array}{l}\text { Fresh vegetable } \\
\text { variety } 2 \text { with dip }\end{array}$ & 4.2 & 4.6 & 9.9 & 9.2 & 82.7 & 67.2 & 77.5 & 81.2 & .69 \\
\hline
\end{tabular}

Notes: An average is provided of 2 trials conducted for each lightly salted vegetable and each herb and spice-seasoned vegetable. A total of 569-670 students bought a lunch on intervention data collection days. Two-sided Mantel-Haenszel tests were used to compare willingness to eat again measures. When $P<.05$, a significant difference existed between the 2 age groups (middle and high school) for the relation between the condition (lightly salted and herb and spice-seasoned) and the willingness to eat again response (yes or no). For middle school, $n=12-66$ responses were collected, depending on the vegetable. For high school, $\mathrm{n}=34-120$ responses were collected, depending on the vegetable. 
Table 2. Vegetable Intake (Control Vs Herb and Spice Seasoned) Among Middle and High School Students $($ Mean \pm SD)

\begin{tabular}{|c|c|c|c|c|}
\hline \multirow[b]{2}{*}{ Vegetable } & \multicolumn{2}{|c|}{ Middle School Students } & \multicolumn{2}{|c|}{ High School Students } \\
\hline & $\begin{array}{l}\text { Lightly Salted } \\
\text { Control }\end{array}$ & $\begin{array}{l}\text { Herb and Spice } \\
\text { Seasoned }\end{array}$ & $\begin{array}{l}\text { Lightly Salted } \\
\text { Control }\end{array}$ & $\begin{array}{l}\text { Herb and Spice } \\
\text { Seasoned }\end{array}$ \\
\hline \multicolumn{5}{|l|}{$\begin{array}{l}\text { Vegetables with condition } \times \\
\text { age group interactions }\end{array}$} \\
\hline Black beans and corn, $\mathrm{g}^{*}$ & $112.1 \pm 57.9^{\mathrm{a}, \mathrm{b}}$ & $71.5 \pm 69.5^{\mathrm{a}}$ & $128.4 \pm 66.9^{\mathrm{a}, \mathrm{b}}$ & $156.5 \pm 64.9^{b}$ \\
\hline Corn and peas, $\mathrm{g}^{\dagger}$ & $120.5 \pm 62.9^{a}$ & $95.1 \pm 61.7^{b}$ & $146.3 \pm 41.6^{\mathrm{a}, \mathrm{b}}$ & $129.7 \pm 50.4^{a}$ \\
\hline \multicolumn{5}{|l|}{$\begin{array}{l}\text { Vegetables with main } \\
\text { effects but not condition } \times \\
\text { age interactions }\end{array}$} \\
\hline Carrots, $\mathrm{g}^{\ddagger}$ & $97.6 \pm 51.2$ & $103.6 \pm 54.1$ & $105.6 \pm 49.1$ & $98.6 \pm 55.8$ \\
\hline Green beans, $\mathrm{g}^{\S}$ & $96.9 \pm 48.9$ & $104.0 \pm 43.2$ & $109.0 \pm 44.2^{a}$ & $93.9 \pm 45.5^{b}$ \\
\hline $\begin{array}{l}\text { Fresh vegetable with dip } \\
\text { (cucumbers, cherry } \\
\text { tomatoes, carrots), g\| }\end{array}$ & $98.5 \pm 57.3^{\mathrm{a}}$ & $118.2 \pm 50.0^{b}$ & $112.4 \pm 4$ & $111.0 \pm 55.1$ \\
\hline $\begin{array}{l}\text { Fresh vegetable with dip } \\
\text { (celery, cauliflower, } \\
\text { cucumbers, cherry } \\
\text { tomatoes), g }\end{array}$ & $106.6 \pm 60.5^{a}$ & $121.3 \pm 54.6^{\mathrm{b}}$ & $115.2 \pm 53.9$ & $118.2 \pm 59.7$ \\
\hline Broccoli, $g^{\#}$ & $110.6 \pm 53.5^{a}$ & $124.4 \pm 46.7^{\mathrm{b}}$ & $126.2 \pm 47.1^{a}$ & $113.7 \pm 50.7^{b}$ \\
\hline Cauliflower, $\mathrm{g}^{\star \star}$ & $106.9 \pm 63.2^{\mathrm{a}}$ & $137.9 \pm 47.0^{b}$ & $136.5 \pm 52.2^{\mathrm{a}}$ & $115.5 \pm 57.6^{6}$ \\
\hline \multicolumn{5}{|c|}{$\begin{array}{l}{ }^{*} \text { Black beans and corn intake in cups ranged from approximately } 1 / 3 \text { to } 2 / 3 ;{ }^{\dagger} \text { Corn and peas intake in cups range from } \\
\text { approximately } 3 / 4 \text { to } 1 ;{ }^{\ddagger} \text { Carrot intake in cups range from approximately } 2 / 3 \text { to } 7 / 10 ;{ }^{\S} \text { Green bean intake in cups ranged from } \\
\text { approximately } 2 / 3 \text { to } 4 / 5 ; \text {; "Fresh vegetables with dip (cucumbers, cherry tomatoes, carrots) intake in cups ranged from } \\
\text { approximately } 2 / 3 \text { to } 3 / 4 ;{ }^{9} \text { Fresh vegetables with dip (celery, cauliflower, cucumbers, cherry tomatoes) intake in cups ranged } \\
\text { from approximately } 3 / 4 \text { to } 4 / 5 ;{ }^{*} \text { Broccoli intake in cups ranged from } 2 / 3 \text { to } 4 / 5 ;{ }^{* *} \text { Cauliflower intake in cups ranged from } 4 / 5 \text { to } 1 \text {. } \\
\text { a,b Different letter superscripts in the table are used to denote mean values that are statistically different from one another at } \\
P<.05 \text {. Data were analyzed with } 2 \text {-way ANOVA testing the impact of age group and condition (control vs herb and spice sea- } \\
\text { soned) on vegetable intake. }\end{array}$} \\
\hline
\end{tabular}

of condition $(P>.05)$. However, post hoc tests indicated that the large quantitative increase for herb and spice vegetables relative to control among high schoolers was not significant $(P=.06)$. High school students also consumed more seasoned black beans and corn than did middle school students $(P<$ .001 ). For corn and peas, middle school students ate more control vegetables than herb and spice seasoned ones $(\mathrm{F} 1,248=13.7, P<.001)$ whereas high school students ate more herb and spice seasoned corn and peas than did middle schoolers $(\mathrm{F} 1,248=10.2$, $P=.002$ ).

Intervention Intake of Vegetables With Main Effects but No Condition by Age Interactions

Intake results for vegetables with main effects but not interactions are shown in Figure 2B and Table 2.
Students consumed more control compared with herb and spice seasoned broccoli $(\mathrm{F} 1,314=6.5, P=0.01)$ irrespective of age. Students also consumed more control compared with seasoned cauliflower (F1,196 $=7.6$, $P=.006$ ), and high schoolers consumed more cauliflower than did middle schoolers regardless of seasoning condition (F1,196 = 15.5, $P<.001)$. For green beans, students consumed more control than herb and spice seasoned vegetables $(\mathrm{F} 1,251=6.3, P=.01)$. Intake of both fresh vegetable options was higher among high schoolers than middle schoolers $(P<.03)$ but was not influenced by seasoning of the dip. These results suggest that for some vegetables, intake of lightly salted control vegetables was higher than for vegetables with added herbs and spices, and high schoolers consumed more vegetables than did middle schoolers.
Follow-Up Exposure Study Selection, Willingness to Eat Again, and Intake

For both Dillicious Broccoli and Fiesta Black Beans and Corn, little change in selection rates occurred from before to after exposure (Table 3). There was an effect of exposure on the proportion of students who chose would eat again for the Dillicious Broccoli $\left(\chi_{\mathrm{MH}}^{2}=9.0,1\right.$ degree of freedom [DF], $P=.003)$. A higher percentage of students in both age groups chose the would eat again option after compared with before exposure (Table 2). The apparent increase in the proportion choosing would eat again from before to after exposure $(66.7 \%$ to 92.3\%) for black beans and corn $\left(\chi_{\mathrm{MH}}^{2}=1.5,1 \mathrm{DF}, P=.22\right)$ was not significant.

For broccoli, the 2-way ANOVA showed a main effect on intake of 
age group $(\mathrm{F} 1,300=16.3, P<.001)$ demonstrating greater intake among high schoolers before and after exposure (Figure 3). The small increase in intake of Dillicious Broccoli from before $(130.1 \pm 59.2 \mathrm{~g})$ to after exposure $(140.9 \pm 49.1 \mathrm{~g})$ also was not significant $(P=.06)$. Conversely, for black beans and corn, no main effects on intake were seen for condition, age, or the condition $\times$ age interaction $(P>.05$ for all $)$.

\section{DISCUSSION}

Previous multicomponent educational programs $^{31,32}$ administered in schools demonstrated minimal effectiveness at increasing vegetable intake among youths. Furthermore, on a practical level, those programs are difficult to implement and sustain within the school lunch setting. ${ }^{33}$ To overcome these challenges, the current study used herbs and spices as a simple, costeffective approach to improving vegetable palatability in the NSLP. The results demonstrated that the changes met or improved students' baseline consumption without using excess sauces, sugar, and fat. However, the use of herbs and spices alone did not produce substantial increases in students' vegetable selection or consumption (compared with adding small amounts of oil and salt) when delivered as part of a short-term intervention. Even so, whereas the intake and selection of lightly salted vegetables was initially higher among this population of rural adolescents, limited exposure to spice blends in the school cafeteria increased students' reported willingness to eat the seasoned vegetables again. This suggests that herbs and spices can be incorporated into school lunch menu planning without adversely affecting intake, even when students have low prior exposure to these flavors. Because herbs and spices were shown to offer protection against a number of chronic diseases, ${ }^{34-36}$ their introduction to adolescents in the context of school lunch may provide broader public health benefits.

Throughout all phases of the intervention, selection rates were low for both control and seasoned vegetables, ranging from approximately 3\% to $18 \%$ of students choosing the target vegetable in any given lunch period. These values were consistent with those observed in other studies conducted in school cafeterias. ${ }^{22}$ Other work ${ }^{37}$ indicated that children's food choices were guided by taste, as opposed to healthfulness, and youths were more likely to
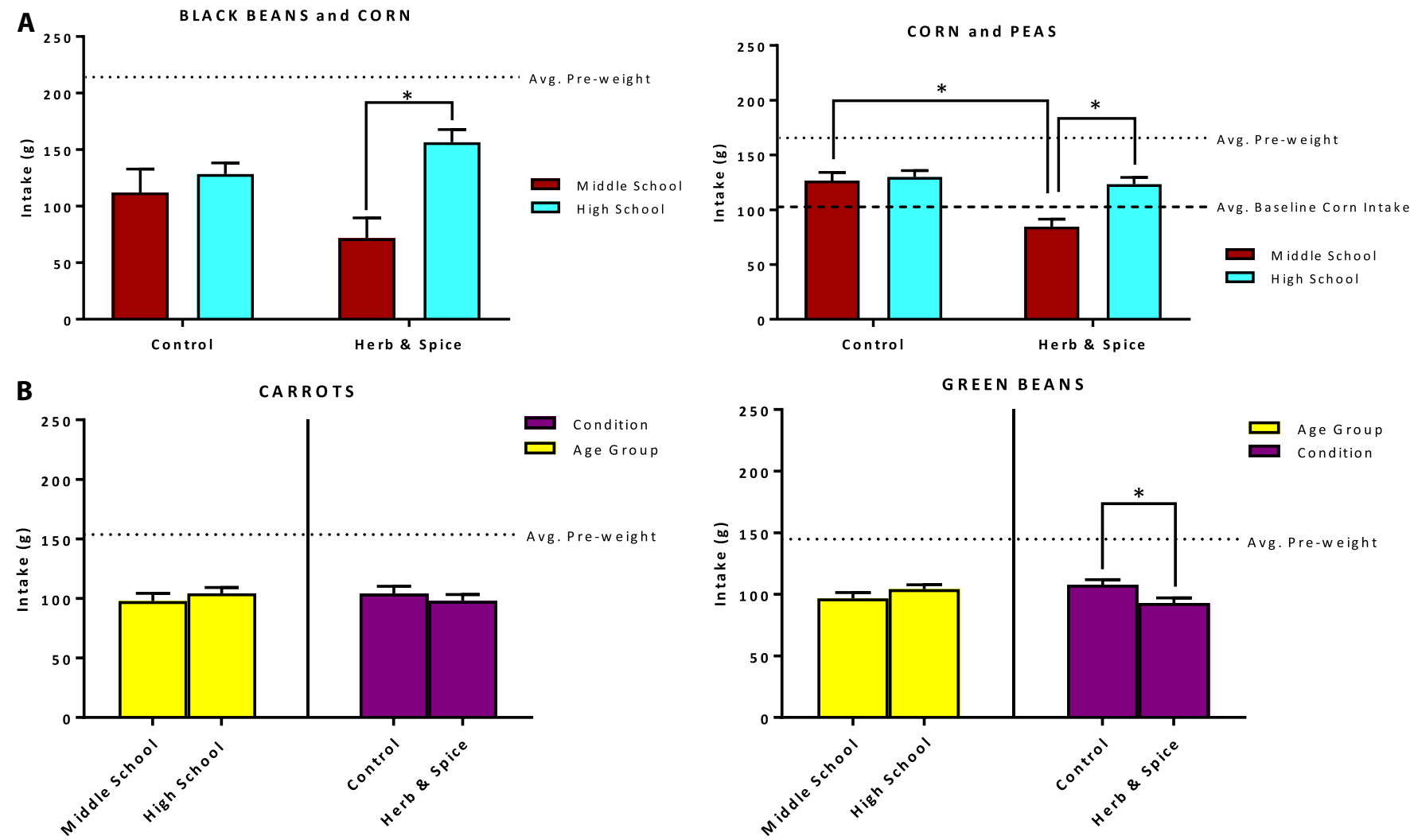

Figure 2. Intake for all intervention vegetables (Veg). (A) Vegetables with significant condition $\times$ age group interactions. (B) Vegetables with main effects but not significant condition $\times$ age group interactions. Average (Avg.) preweight of vegetable and baseline intake measures (when available) are marked on each graph with dotted lines. Intakes from each 2 trials conducted for each control and each seasoned vegetable were compiled before analysis. For the middle school age group, $n=10-66$, depending on the vegetable. For the high school age group, $n=34-118$, depending on the vegetable. Statistical tests performed with 2-way ANOVA with independent variables of condition (control vs herb and spice seasoned) and age group (middle school vs high school) and statistical significance at $P<.05$. *Significant differences between groups. 
FRESH VEG VARIETY \# 1 with DIP

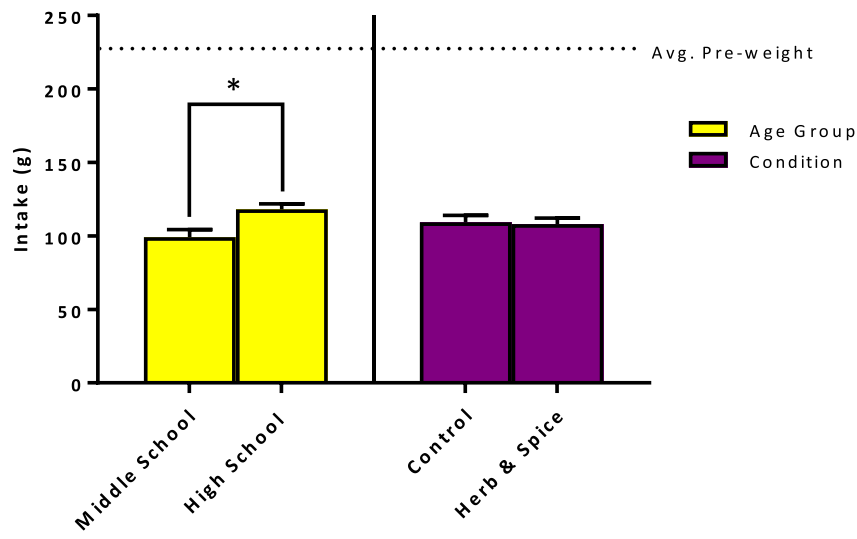

B RO C COLI

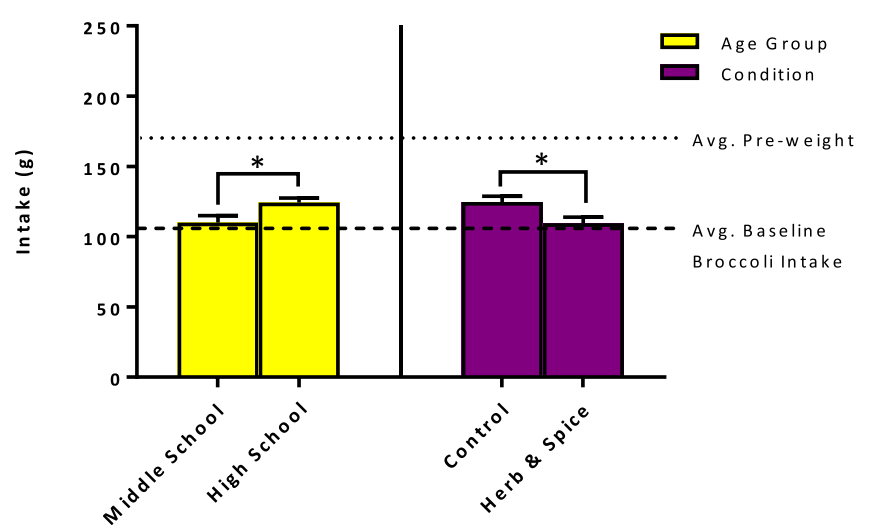

FRESH VEG VARIETY \# 1 with DIP

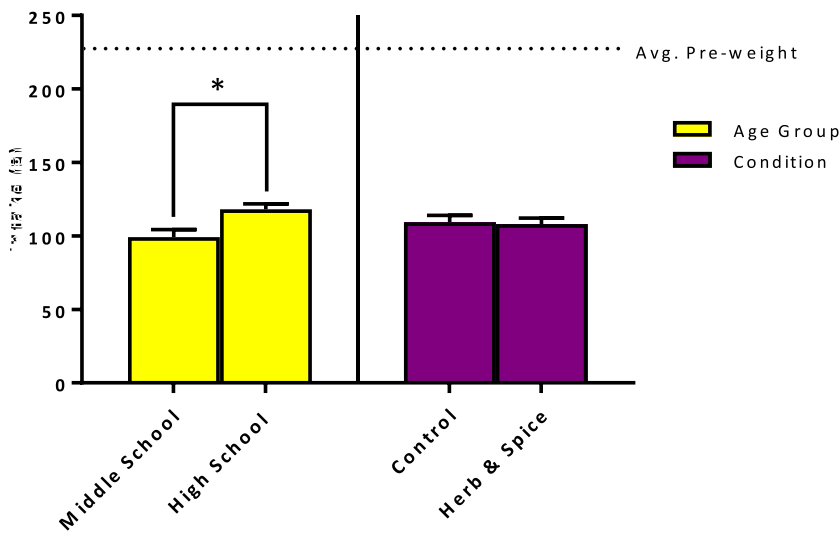

CAULIFLOWER

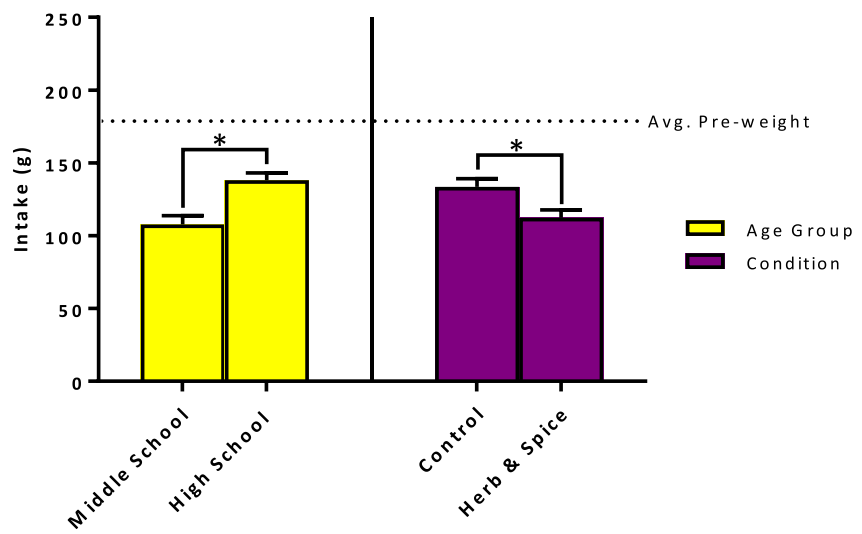

Figure 2. (Continued)

choose unhealthy than healthy snacks when provided with both. ${ }^{38}$ Furthermore, children were more likely to choose fruit than vegetable snack options. ${ }^{39}$ Thus, it seems likely that the low selection rates observed here may have been caused by the presence of competing food choices. That is, students were offered a variety of choices (eg, juices, fresh and canned fruits, other vegetables) and were not compelled to take the target vegetable, so it is reasonable to speculate that competing fruits and vegetables reduced selection of the target recipes. Although selection rates did not vary between conditions (control vs herb and spice), high schoolers selected both varieties more often than did middle schoolers. Because older adolescents likely had more exposure to a variety of foods and tend to be less neophobic compared with younger children, ${ }^{40}$ they may have been more willing to try the new vegetable preparations.
Nonetheless, selection rates in both age groups remained low, which underscores the need to identify additional strategies that can increase vegetable selection in the school lunch setting. Other studies ${ }^{41}$ ${ }_{-45}$ observed increases in students' vegetable selection in response to interventions that combined environmental nudges with improvements in vegetable palatability. For example, Cohen and colleagues ${ }^{41}$ encouraged fruit and vegetable selection by offering them at the beginning of the line, serving them in attractive containers, and pairing them with colorful images and signage. After 3 months' exposure to the intervention, the researchers observed a $>10 \%$ increase in the proportion of students selecting vegetables. ${ }^{41}$ Comparatively, the scaleddown approach used in the current study may have been of insufficient dose and length to see meaningful improvements in vegetable selection.
During the intervention, most students $(67.2 \%$ to $98.1 \%)$ who chose the vegetable said that they would eat it again regardless of whether it was served lightly salted or with added herbs and spices. This suggests that novel seasoning blends could be added to enhance the variety of flavors served in the school lunch program without adversely affecting students' willingness to consume the products again. However, students were more likely to choose the would eat again option when the lightly salted control vegetables were served, potentially owing to the novelty of the herbs and spices. Prior interventions $^{41,46,47}$ that used herbs and spices to improve palatability of school lunch offerings observed increased consumption, but only after several months of repeated exposure to the new preparations. In addition to a lack of familiarity with the spice blends, it is possible that adding herbs and spices might 


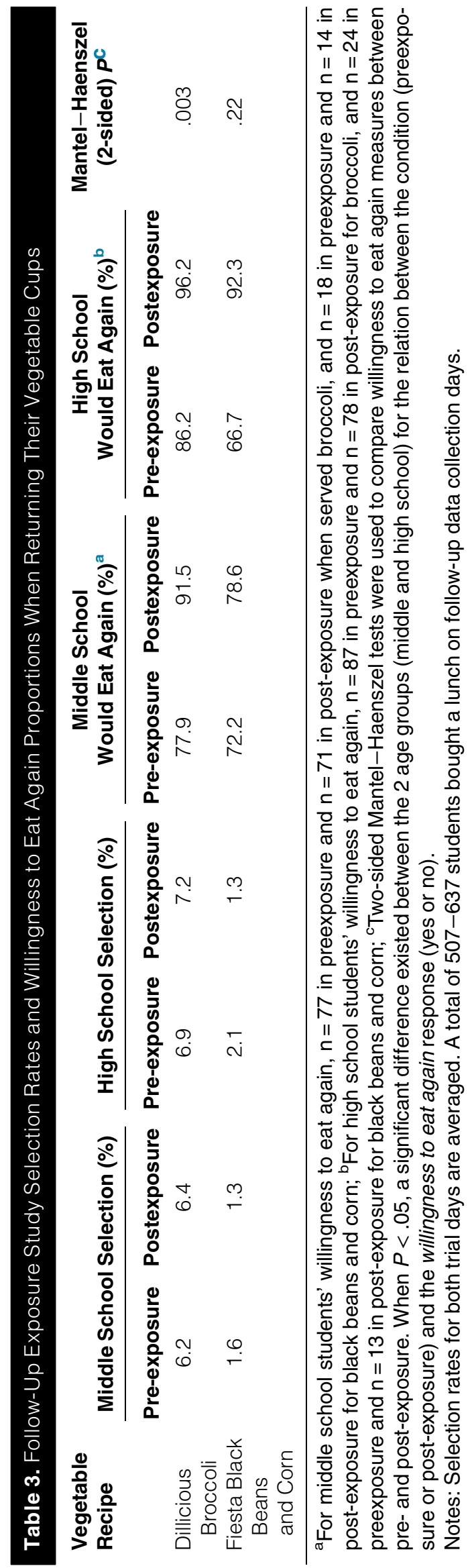

have masked other positive sensory attributes in the vegetables. For example, Carney and colleagues ${ }^{48}$ found that in descriptive panels with adults, carrots seasoned with oil and salt alone were perceived as more buttery than were carrots seasoned with oil, salt, herbs, and spices, so it is possible that adding some seasonings had unintended effects on the sensory profile of the vegetables. In addition, salt can reduce the perception of bitterness, ${ }^{49}$ which may further explain why students initially favored the control vegetables.

For the main intervention, it was hypothesized that students would consume more vegetables with herbs and spices because those recipes were liked and preferred over the control recipes in an earlier study conducted in the same setting. ${ }^{27}$ Contrary to expectations, students tended to consume more control vegetables. Although the high school students liked the seasoned recipes better during taste tests, this did not necessarily translate to greater intake. There are several possible explanations for this discrepancy. First, lower intake than expected of seasoned vegetables might have been caused by low herb and spice exposure more generally, as supported by previous work. ${ }^{27}$ The high schoolers might have had relatively low herb and spice exposure, but they tended to consume more seasoned vegetables than did the middle schoolers. This suggests that the younger age group might be more limited in dietary exposure. Second, because vegetable selection rates were low owing to the number and variety of competing food choices, it is likely that selection bias might have influenced the results of the intervention. That is, students who selected the target vegetable probably did so because they had high liking for the taste of the vegetable itself. For those students, the herbs and spices might have been unexpected, particularly if they were accustomed to consuming that vegetable without seasonings.

Limitations of the current work should be recognized. First, the study lacked a true control group to account for the effect of time on vegetable intake, and although the researchers collected baseline measurements to 


\section{Dillicious Broccoli}

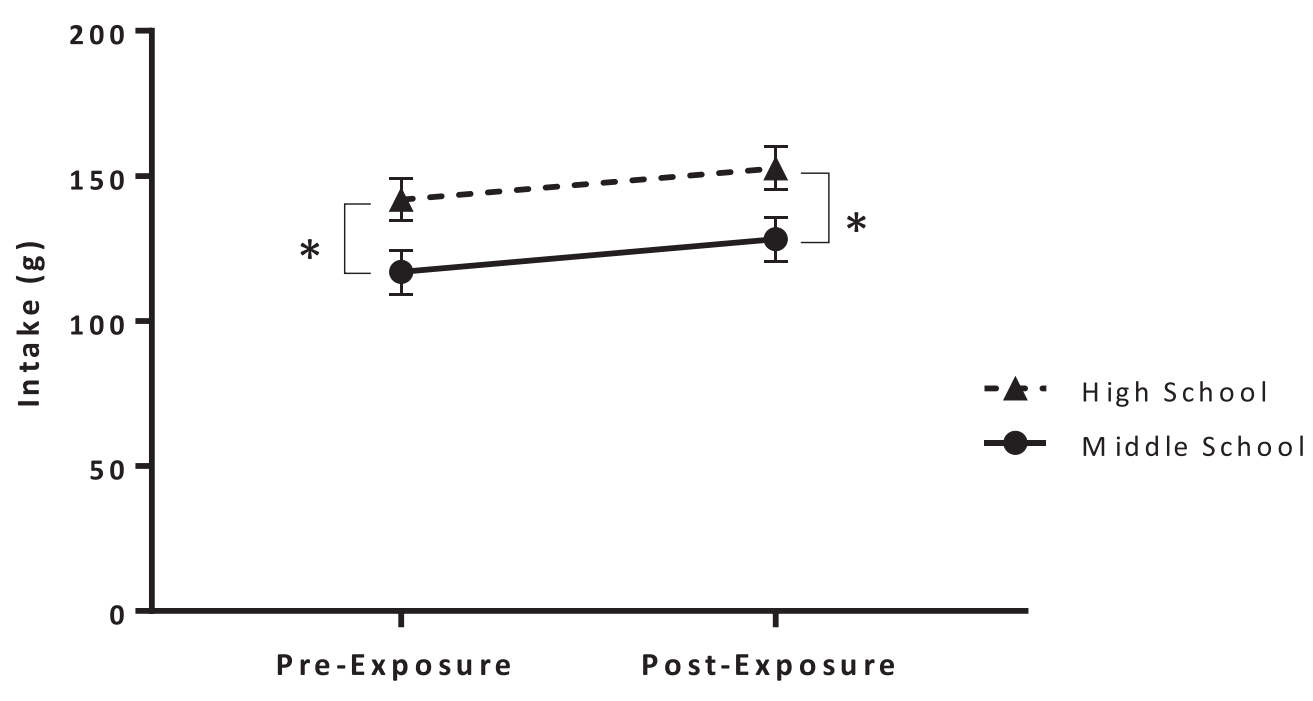

Fiesta Black Beans and Corn

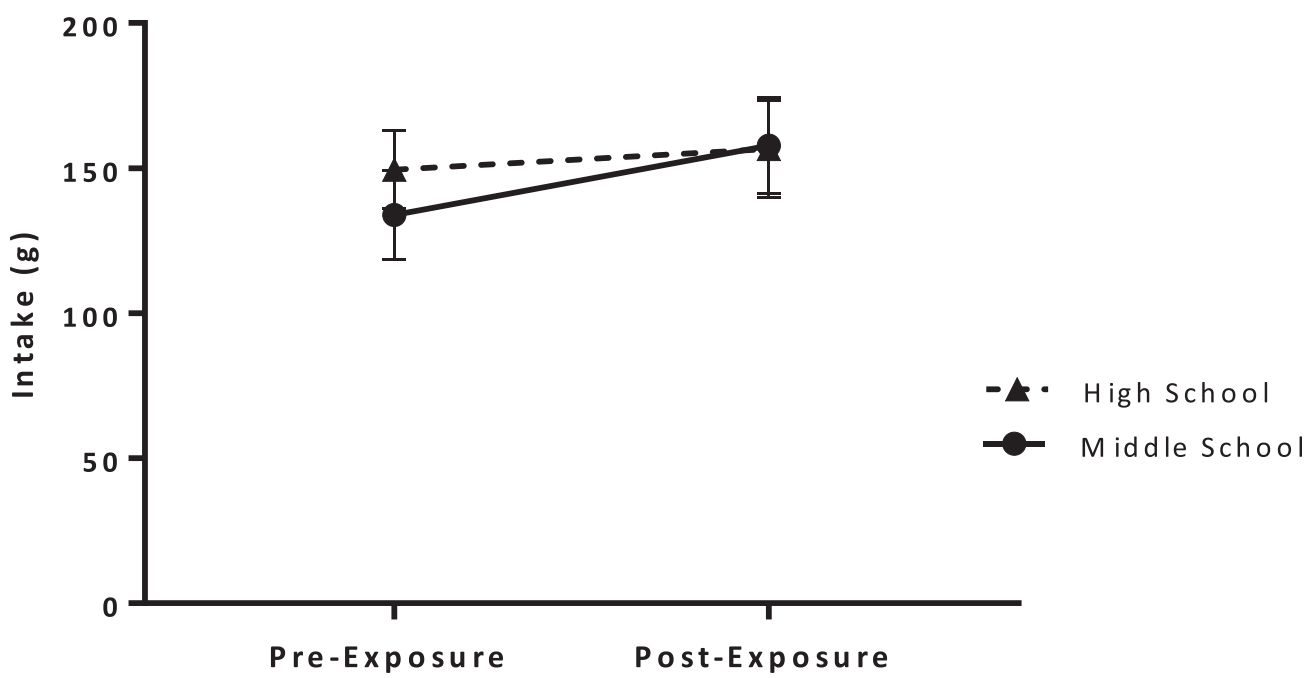

Figure 3. Average intake and SE bars for Dillicious Broccoli and Fiesta Black Beans and Corn at pre- and postexposure time points. For broccoli, 2-way ANOVA showed a main effect on intake of age group (middle or high school) $(\mathrm{F} 1,300=16.3, P<.001)$. The main effect of condition (pre- vs postexposure) on intake was not significant $(F 1,300)=3.3, P=.07)$. Fisher's least significant difference post hoc tests showed that high schoolers ate more broccoli than did middle schoolers $(P<.001)$. For black beans and corn, no main effects on intake were seen for condition, age, or condition by age ( $P>.05$ for all). For middle school students, $\mathrm{n}=74$ (pre-exposure) and 71 (postexposure) for broccoli and $n=18$ (pre) and 15 (post) for black beans and corn. For high school students, $n=83$ (pre) and 76 (post) for broccoli and $n=23$ (pre) and 15 (post) for black beans and corn. ${ }^{\star} P<.05$.

estimate student intake before the intervention, the serving sizes and preparation methods differed, which limited the statistical comparisons that could be made. Second, there were small sample sizes for most analyses, and because entrées and other side dishes offered were at the discretion of the cafeteria staff during the intervention phase, variability owing to competing foods might have reduced student selection and intake of the target vegetables. Related to this, there were large SDs in intake, particularly for vegetables that were novel to the school (eg, black beans). This affected the power of the statistical analyses. To maximize participation, students were not required to complete consent forms; however, as a result, individual students could not be tracked, and thus conclusions can be made only at the school level. 


\section{IMPLICATIONS FOR RESEARCH AND PRACTICE}

Findings of the current study demonstrate that within the context of a short-term intervention, herbs and spices did not increase consumption of vegetables among rural adolescents, but with minimal repeated exposure, these flavors might become accepted. Introducing novel herbs and spices on familiar vegetables first might be beneficial to encourage children and adolescents to taste and gain exposure to these flavors. Identifying strategies to increase selection, particularly in the school cafeteria setting, is also imperative. For these reasons, if school food service directors choose to integrate herbs and spices into school lunches, they could provide them over multiple exposures. A greater understanding of the individual- and school-level variables that affect the acceptance and intake of vegetables seasoned with herbs and spices is an important area for future investigation.

\section{ACKNOWLEDGMENTS}

This research was funded by a grant to primary investigator Keller from the McCormick Science Institute as well as US Department of Agriculture Hatch Act funds (PEN04565). The authors would like to thank the sensory scientists and research chefs at the McCormick Science Institute for the development of the recipes for these studies. They also thank the students and staff at the participating school for their assistance and collaboration throughout the studies.

\section{SUPPLEMENTARY DATA}

Supplementary data related to this article can be found at https://doi. org/10.1016/j.jneb.2019.04.016.

\section{REFERENCES}

1. Cullen KW, Chen TA. The contribution of the USDA school breakfast and lunch program meals to student daily dietary intake. Prev Med Rep. 2017;5:82-85.

2. US Department of Agriculture, Food and Nutrition Service. National School Lunch Program and School Breakfast
Program: Nutrition Standards for All Foods Sold in School as Required by the Healthy, HungerFree Kids Act of 2010; Interim Final Rule. Fed Regist. 2013;78:39068-39120. https://www. govinfo.gov/content/pkg/FR-201306-28/pdf/2013-15249.pdf. Accessed May 7, 2019.

3. Food and Nutrition Service (FNS). US Department of Agriculture. Nutrition standards in the National School Lunch and School Breakfast Programs. Final rule. Fed Regist. 2012;77:4088-4167.

4. Schwartz MB, Henderson KE, Read M, Danna N, Ickovics JR. New school meal regulations increase fruit consumption and do not increase total plate waste. Childhood Obes. 2015;11:242-247.

5. Cohen JFW, Richardson S, Parker E, Catalano PJ, Rimm EB. Impact of the new U.S. Department of Agriculture school meal standards on food selection, consumption, and waste. Am J Prev Med. 2014;46:388-394.

6. Cullen KW, Chen TA, Dave JM. Changes in foods selected and consumed after implementation of the new National School Lunch Program meal patterns in southeast Texas. Prev Med Rep. 2015;2:440-443.

7. Tajkarimi MM, Ibrahim SA, Cliver DO. Antimicrobial herb and spice compounds in food. Food Control. 2010;21:1199-1218.

8. Polsky S, Beck J, Stark RA, Pan Z, Hill JO, Peters JC. The influence of herbs, spices, and regular sausage and chicken consumption on liking of reduced fat breakfast and lunch items. J Food Sci. 2014;79:S2117-S2126.

9. Ghawi SK, Rowland I, Methven L. Enhancing consumer liking of low salt tomato soup over repeated exposure by herb and spice seasonings. Appetite. 2014;81:20-29.

10. Wang C, Lee Y, Lee S-Y. Consumer acceptance of model soup system with varying levels of herbs and salt. J Food Sci. 2014;79:S2098-S2106.

11. Manero J, Phillips C, Ellison B, Lee SY, Nickols-Richardson SM, ChapmanNovakofski KM. Influence of seasoning on vegetable selection, liking and intent to purchase. Appetite. 2017;116:239245.

12. Boeing $\mathrm{H}$, Bechthold A, Bub A, et al. Critical review: vegetables and fruit in the prevention of chronic diseases. Eur J Nutr. 2012;51:637-663.

13. Moore LV, Thompson FE, Demissie Z. Percentage of youth meeting federal fruit and vegetable intake recommendations, Youth Risk Behavior Surveillance System, United States and 33 states, 2013. J Acad Nutr Diet. 2017; 117:545-553. e3.

14. Cooke LJ, Wardle J. Age and gender differences in children's food preferences. Br J Nutr. 2005;93:741-746.

15. Cox DN, Melo L, Zabaras D, Delahunty CM. Acceptance of health-promoting Brassica vegetables: the influence of taste perception, information and attitudes. Public Health Nutr. 2012;15:1474-1482.

16. Dinehart ME, Hayes JE, Bartoshuk LM, Lanier SL, Duffy VB. Bitter taste markers explain variability in vegetable sweetness, bitterness, and intake. Physiol Behav. 2006;87:304-313.

17. Mc Morrow L, Ludbrook A, Macdiarmid JI, Olajide D. Perceived barriers towards healthy eating and their association with fruit and vegetable consumption. $J$ Public Health (Oxf). 2017;39:330-338.

18. Krolner R, Rasmussen M, Brug J, Klepp KI, Wind M, Due P. Determinants of fruit and vegetable consumption among children and adolescents: a review of the literature. Part II: qualitative studies. Int J Behav Nutr Phys Act. 2011;8:112.

19. Mennella JA, Reiter AR, Daniels LM. Vegetable and fruit acceptance during infancy: impact of ontogeny, genetics, and early experiences. $A d v$ Nutr. 2016;7:211S-219S.

20. Dinnella C, Morizet D, Masi C, et al. Sensory determinants of stated liking for vegetable names and actual liking for canned vegetables: a cross-country study among European adolescents. Appetite. 2016;107:339-347

21. Parmer SM, Salisbury-Glennon J, Shannon D, Struempler B. School gardens: an experiential learning approach for a nutrition education program to increase fruit and vegetable knowledge, preference, and consumption among second-grade students. J Nutr Educ Behav. 2009;41:212-217.

22. Miller N, Reicks M, Redden JP, Mann T, Mykerezi E, Vickers Z. Increasing portion sizes of fruits and vegetables in an elementary school lunch program can increase fruit and vegetable consumption. Appetite. 2015;91:426-430.

23. Wengreen HJ, Madden GJ, Aguilar SS, Smits RR, Jones BA. Incentivizing children's fruit and vegetable 
consumption: results of a United States pilot study of the Food Dudes Program.J Nutr Educ Behav. 2013;45:54-59.

24. Savage JS, Peterson J, Marini M, Bordi PL, Birch LL. The addition of a plain or herb-flavored reduced-fat dip is associated with improved preschoolers' intake of vegetables. J Acad Nutr Diet. 2013;113:1090-1095.

25. Kim SA, Moore LV, Galuska D, et al. Vital signs: fruit and vegetable intake among children-United States, 20032010. MMWR Morb Mortal Wkly Rep. 2014;63:671-676.

26. Kimura S, Endo Y, Minamimae K, Kanzaki S, Hanaki K. Gender differences in childhood food preference: evaluation using a subjective picture choice method. Pediatr Int. 2013;56:389-394.

27. Fritts JR, Fort C, Quinn Corr A, et al. Herbs and spices increase liking and preference for vegetables among rural high school students. Food Qual Prefer. 2018;68:125-134.

28. Johnson JA III, Johnson AM. Urbanrural differences in childhood and adolescent obesity in the United States: a systematic review and meta-analysis. Child Obes. 2015;11:233-241.

29. Herman CP, Mack D. Restrained and unrestrained eating. J Pers. 1975;43:647660.

30. Pennsylvania Department of Education. National School Lunch Program. Reports 2017 Data. http://www.education.pa. gov/Teachers\%20-\%20Administrators/ Food-Nutrition/Pages/NationalSchool-Lunch-Program-Reports.aspx. Accessed May 7, 2019.

31. Cleghorn CL, Greenwood DC, Cade JE, Christian MS, Evans CE. Systematic review and meta-analysis of schoolbased interventions to improve daily fruit and vegetable intake in children aged 5 to 12 y. Am J Clin Nutr. 2012;96:889-901.

32. Lytle LA, Murray DM, Perry CL, et al. School-based approaches to affect adolescents' diets: results from the TEENS study. Health Educ Behav. 2004;31:270-287.

33. Datta J, Petticrew M. Challenges to evaluating complex interventions: a content analysis of published papers. BMC Public Health. 2013;13:568.

34. Zheng J, Zhou Y, Li Y, Xu D-P, Li S, Li H-B. Spices for prevention and treatment of cancers. Nutrients. 2016;8:495.

35. Shan B, Cai YZ, Sun M, Corke H. Antioxidant capacity of 26 spice extracts and characterization of their phenolic constituents. J Agric Food Chem. 2005;53:7749-7759.

36. Qin Y, Ran L, Wang J, et al. Capsaicin supplementation improved risk factors of coronary heart disease in individuals with low HDL-C levels. Nutrients. 2017;9(9).

37. Heard AM, Harris JL, Liu S, Schwartz MB, Li X. Piloting an online grocery store simulation to assess children's food choices. Appetite. 2016;96:260267.

38. Beets MW, Tilley F, Kyryliuk R, Weaver RG, Moore JB, TurnerMcGrievy G. Children select unhealthy choices when given a choice among snack offerings. $J$ Acad Nutr Diet. 2014;114:1440-1446.

39. Roe LS, Meengs JS, Birch LL, Rolls BJ. Serving a variety of vegetables and fruit as a snack increased intake in preschool children. Am J Clin Nutr. 2013;98:693699.

40. Nicklaus S, Boggio V, Chabanet C, Issanchou S. A prospective study of food variety seeking in childhood, adolescence and early adult life. Appetite. 2005;44:289-297.

41. Cohen JFW, Richardson SA, Cluggish SA, Parker E, Catalano PJ, Rimm EB. Effects of choice architecture and chefenhanced meals on the selection and consumption of healthier school foods: a randomized clinical trial. JAMA Pediatr. 2015;169:431-437.
42. Skov LR, Lourenço S, Hansen GL, Mikkelsen BE, Schofield C. Choice architecture as a means to change eating behaviour in self-service settings: a systematic review. Obes Rev. 2013;14: 187-196.

43. Haerens L, De Bourdeaudhuij I, Maes L, Vereecken C, Brug J, Deforche B. The effects of a middle-school healthy eating intervention on adolescents' fat and fruit intake and soft drinks consumption. Public Health Nutr. 2007;10: 443-449.

44. Reicks M, Redden JP, Mann T, Mykerezi E, Vickers Z. Photographs in lunch tray compartments and vegetable consumption among children in elementary school cafeterias. JAMA. 2012;307:784-785.

45. Redden JP, Mann T, Vickers Z, Mykerezi E, Reicks M, Elsbernd S. Serving first in isolation increases vegetable intake among elementary schoolchildren. PloS One. 2015;10:e0121283.

46. Zellner DA, Cobuzzi JL. Eat your veggies: a chef-prepared, family style school lunch increases vegetable liking and consumption in elementary school students. Food Qual Prefer. 2017;55:8-15.

47. Cohen JFW, Smit LA, Parker E, et al. Long-term impact of a chef on school lunch consumption: findings from a 2year pilot study in Boston middle schools. J Acad Nutr Diet. 2012;112: 927-933

48. Carney EM, Stein WM, Reigh NA, et al. Increasing flavor variety with herbs and spices improves relative vegetable intake in children who are propylthiouracil (PROP) tasters relative to nontasters. Physiol Behav. 2018;188:4857.

49. Bakke AJ, Stubbs CA, McDowell EH, Moding KJ, Johnson SL, Hayes JE. Mary Poppins was right: adding small amounts of sugar or salt reduces the bitterness of vegetables. Appetite. 2018; 126:90-101. 


\section{CONFLICT OF INTEREST}

B. J. Rolls is a member of the McCormick Science Institute Advisory Board. The rest of the authors have not stated any conflicts of interest. 